\title{
"Nossa Senhora da Help": sexo, turismo e deslocamento transnacional em Copacabana*
}

\author{
Ana Paula da Silva** \\ Thaddeus Blanchette ${ }^{* * *}$
}

Resumo

A análise do turismo sexual e o tráfico das mulheres tem concentrada na subjugação das mulheres, situando-as como passivas - objetos de câmbio que são "traficados" entre universos nacionais subordinados e dominantes. Todavia, como LéviStrauss advém, as mulheres também são geradoras de símbolos. Baseando nossa análise em trabalhos de campo feito entre turistas sexuais e prostitutas em Copacabana, buscamos demonstrar como a capacidade feminina de criar e manipular símbolos potencializa o movimento internacional de brasileiras e de estrangeiros.

Palavras-chave: Turismo Sexual, P rostituição, Copacabana, Tráfico de Mulheres, Gringos.

\footnotetext{
* Recebido para publicação em julho de 2005, aprovado em setembro de 2005.

** Doutoranda, PPGSA, IFCS, UFRJ . Rio de J aneiro-RJ .

${ }^{* * *}$ Doutorando, PPGAS, Museu Nacional, UFRJ, Rio de J aneiro-RJ . macunaima30@yahoo.com.br
} 
sexo, turismo e deslocamento transnacional em Copacabana

"Our Lady of Help":

Sex, Tourism and Transnational Movements in Copacabana

Abstract

Analysis of sexual tourism has concentrated on the subjugation of women as devalued objects of exchange, trafficked between dominant and subordinate national universes. As Lévi-Strauss points out, however, while often understood to be items of exchange, women are also symbol generators in their own right. It is this symbolic-generating capacity that strengthens the international movement of Brazilian women as sexualized objects of exchange. Basing our analysis on fieldwork among tourists and prostitutes in Copacabana, we seek to demonstrate how women's ability to manipulate symbols potentializes the international movement of Brazilian women and foreign men.

Key Words: Sexual Tourism, Prostitution, Copacabana, Trafficking of Women, $G$ ringos. 
Ana Paula da Silva

Thaddeus Blanchette

Introdução

As articulações entre turismo, sexo e migração têm sido cada vez mais discutidas no mundo. Todavia, existe uma tendência nesse debate a utilizar termos de denúncia ou acusação como se fossem categorias de análise. Tal confusão expressa-se na construção da figura do turista sexual, um personagem nitidamente caracterizado nos discursos de atores envolvidos na luta contra o turismo sexual e o tráfico das mulheres no Brasil. Nestes, o turista sexual, por meio de seu suposto aliciamento predatório de meninas ingênuas, é tipicamente apresentado como um agente privilegiado na transformação de brasileiras em vítimas do tráfico internacional das mulheres. Esta visão está longe de considerar essas mulheres como agentes ativas na construção de seus destinos, assim como de contemplar qualquer noção mais nuançada sobre "o" turista sexual. E, o que é mais grave, essa procura de vítimas e vilões oculta o funcionamento das relações que constituem os nexos entre turismo internacional, migração e sexo operando na maioria das grandes cidades brasileiras.

A partir de uma pesquisa realizada em uma abordagem antropológica, nosso intuito no presente trabalho é realizar uma crítica às análises que reduzem o complexo jogo de interesses e de agentes que configuram o turismo sexual no Rio de J aneiro a uma equação simples e maniqueísta. Em particular, interessa-nos mostrar os indivíduos como atores principais dos dramas vividos na interseção entre turismo e sexo.

0 atual artigo é fruto de um trabalho de campo efetuado no Baixo Copacabana, área entendida como uma região moral tipificada pela presença de prostitutas e de estrangeiros. ${ }^{1}$ Trata-se de uma primeira abordagem a uma conjunção de códigos, valores e agentes que articula continentes e universos sociais

1 Gaspar, Maria Dulce. Garotas de Programa. Prostituição em Copacabana e Id entidade So cial. Rio de J aneiro, J orge Zahar, 1984. 
sexo, turismo e deslocamento transnacional em Copacabana

extremamente diversos. Nossa intenção aqui não é formular uma representação completa desse nexo, mas sim de apresentá-lo à luz das interlocuções comuns de alguns de seus freqüentadores típicos, seguindo os procedimentos de pesquisa de campo antropológico desenvolvidos por Malinowski. ${ }^{2}$ Esse procedimento coloca em questão a equação vítima/vitimizador, freqüentemente utilizada na formulação de políticas públicas que visam enfrentar o turismo sexual no Brasil.

Considerando as prostitutas como trabalhadoras sexuais e como agentes ativas nas construções de suas vidas, propomos ampliar o debate sobre as ligações entre turismo, prostituição e migração. Nosso intuito é ilustrar determinadas interações entre mulheres brasileiras e homens estrangeiros em Copacabana, evitando, por enquanto, a problemática do turismo sexual homossexual, ou variantes possíveis envolvendo brasileiros e estrangeiras. Destacamos que nossas descobertas são particulares a esse universo e não necessariamente ao Brasil como um todo. Nossos dados indicam que, pelo menos no Rio, as interações sexuais entre estrangeiros e brasileiras são mais complexas do que aquelas delineadas nos modelos hegemônicos de turismo sexual. Deixaremos a aplicabilidade de nossas conclusões ao resto do Brasil para outros momentos e pesquisadores, salientando a extensa obra de Adriana Piscitelli como um bom começo para o leitor interessado em análises semelhantes de outros turismos sexuais em diferentes localidades. ${ }^{3}$

Discursos sobre turismo sexual no Brasil

Nos discursos produzidos por órgãos do governo brasileiro acerca do fenômeno, é comum observar o uso do conceito de turismo sexual como se fosse sinônimo de abuso de menores e

\footnotetext{
2 Malinowski, B. Coral Gardens and Their Magic. London, George Allen and Unwin Ltd, 1935.

3 Piscitelli, Adriana. On gringos and natives: gender and sexuality in the context of international sex to urism in Fortaleza, B razil. Vibrant, vol.1, \# 1, 2004.
} 
Ana Paula da Silva

Thaddeus Blanchette

intimamente vinculado à extradição de mulheres para trabalhos forçados como prostitutas. ${ }^{4}$ Essa visão aparece quase como uma definição oficial do fenômeno - aquela que é a mais comumente usada por agentes políticos para justificar novos dispositivos legais.

Todavia, o turismo sexual parece ser definido no campo legal-jurídico brasileiro de forma diferente, como algo muito mais específico: a violação por estrangeiros das leis brasileiras que regulam o comportamento sexual, mais precisamente, as leis contra pornografia, sedução, estupro, corrupção de menores, atentado violento ao pudor e tráfico de mulheres. ${ }^{5}$ É mister salientar que a simples contratação dos serviços de uma prostituta maior de idade não configura, por si só, um crime e, portanto, não deve ser entendida como turismo sexual nesta acepção do fenômeno.

No plano do senso comum, porém, o turismo sexual é sinônimo do comportamento normativo dos turistas estrangeiros que freqüentam as metrópoles costeiras brasileiras. De acordo com esta noção, turista sexual é aquele estrangeiro que busca parceiras nas praias do Brasil, seja qual for a qualificação legal e/ou social de tal busca. É mister salientar que a definição popular é preferencialmente aplicada àqueles estrangeiros que alugam os serviços de prostitutas. Todavia, seu uso pode ser expandido para contemplar qualquer estrangeiro. $\mathrm{Na}$ acepção popular do fenômeno, a preocupação com a legalidade das atividades visadas é menos importante do que o reforço de um código moral que estipula que os estrangeiros não devem ter contatos sexuais

\footnotetext{
${ }^{4}$ De fato, em recentes apresentações no Rio de Janeiro por agentes da Polícia Federal e a pela Secretaria do Estado de Direitos Humanos, os conceitos de turismo sexual, abuso de menores e tráfico internacional das mulheres têm sido apresentados como quase intercambiáveis.

${ }^{5}$ Por um exemplo claro desse tipo de formulação, veja a Campanha Contra Exploração Sexual (CEDECA-BA), disponível em http://www.violenciasexual. org.br
} 
sexo, turismo e deslocamento transnacional em Copacabana

promíscuos com as nativas. A solução nessa visão do fenômeno é a repressão das mulheres e a expulsão dos homens.

Uma última visão do turismo sexual é oferecida pela Organização Mundial de Trabalho, que o descreve como viagens organizadas que utilizam as estruturas da indústria de turismo com os fins principais de facilitarem o comércio sexual entre turistas e nativos. ${ }^{6}$ Note-se que essa acepção - que poderíamos rotular de uma definição pragmática - ignora a questão da legalidade das atividades promulgadas e se concentra nas práticas e nos objetivos dos turistas, presumindo que estes podem ser distinguidos, com uma certa clareza, dos turistas "normais".

As descontinuidades entre essas definições são óbvias. Todavia, existe um fator que as unifica: a crença de que 0 problema é centrado no comportamento sexual de gringos ${ }^{7}$ em suas interações com nativas. E é lá que reside a confusão epistemológica presente na consideração do problema, pois turista pode ser, em última análise, qualquer estrangeiro que entra no país e, obviamente, essas pessoas não deixam de ser seres sexuais apenas porque passaram a fronteira. 0 termo turista sexual, então, seria melhor entendido como uma acusação aplicável a qualquer estrangeiro no Brasil, desde que o seu comportamento sexual não esteja de acordo com os padrões estabelecidos para os gringos (e que pode ser, enfim, qualquer comportamento sexual que ofende algum nativo). 0 ponto lógico para começar a analisar o fenômeno, então, é indagar quem é quase sempre indicado como turista sexual em uma determinada seleção de gringos.

\footnotetext{
${ }^{6}$ VieiRa de Carvalho, Rodrigo José. 0 turismo sexual: uma realidade brasileira em pauta. http://www.estudosturisticos.com.br/.

7 Usamos o termo gringo seguindo Blanchette, como sinônimo para "aquele que não é da gente mas que está entre nós". (BLANCHETTE, Thaddeus. G ringos. Tese de mestrado, PPGAS, Museu Nacional, UFRJ, 2001, sob a orientação de Dra. Giralda Seyferth.) É mister salientar aqui que gringo, no Brasil, não é termo pejorativo e é uma palavra aplicável a qualquer estrangeiro.
} 
Ana Paula da Silva

Thaddeus Blanchette

Sexo (e gringos) na cidade

Encontramos a categoria turista sexual pela primeira vez durante uma pesquisa sobre a presença estrangeira anglófona no Rio de Janeiro, que resultou na dissertação de mestrado de um dos pesquisadores do presente artigo. ${ }^{8}$ Durante seu trabalho de campo, este descobriu que existia um lugar que todos seus entrevistados - gringos residentes de longo prazo na cidade disseram evitar: a boate $\mathrm{Help}^{9}$, em Copacabana, popularmente entendido como o "local mais gringo do Rio de J aneiro". Era um lugar que todo informante afirmara ter visitado apenas uma vez, dizendo-se horrorizado em função dos turistas sexuais que freqüentam a boate. Segundo um deles:

Eu não sou que nem esses homens patéticos que devem ser proibidos de entrar no Brasil; me deixam com nojo e vergonha e, por sua causa, quase nunca vou a Copacabana, pois não quero ser confundido com eles. Ademais, não preciso ir, né?

Foi essa segunda afirmação que nos intrigou. O que significava, afinal, "precisar ir" a Copacabana?

\footnotetext{
8 IB., ID.

9 É comum nos estudos antropológicos alterar os nomes dos lugares com o fim de garantir o anonimato dos agentes a eles vinculados. No entanto, a boate $\mathrm{Help}$ é tão sui generis que é difícil pensar que qualquer pseudônimo poderia adequadamente ocultar a identidade do local. Ademais, a gerência da Help faz questão que a boate seja internacionalmente reconhecida como o maior e mais famoso local de encontro entre "meninas" brasileiras e turistas estrangeiros. Portanto, adotamos, excepcionalmente, uma ética diferenciada nesse trabalho quando falamos da Help. Em vez de tentar manter a boate anônima, concentramos apenas em detalhar e analisar as relações normativas dentro do lugar, que são ampla e publicamente divulgadas pela gerência ou acessíveis a qualquer pessoa que entra em suas áreas públicas. Outros informantes e estabelecimentos apontados nesse trabalho permanecem anônimos.
} 
sexo, turismo e deslocamento transnacional em Copacabana

Descobrimos que, apesar de os informantes estrangeiros residentes, entrevistados no estudo Gringos, diferenciarem-se dos turistas sexuais, a maioria desses auto-rotulados "gringos bons" vislumbra o Rio - e o sexo e o amor na cidade - através de uma lente forjada pelas mesmas predisposições anunciadas por homens estrangeiros que são identificados (e que se autoidentificam) como turistas sexuais. Ademais, essas predisposições, repetidas também por vários nativos, estão longe de ser somente "uma coisa de gringo".

Em primeiro lugar, o Rio é considerado como parte da altermetade de uma realidade bipolar composta por instâncias dominantes e subordinadas. Nesse modelo, a cidade é concebida, no eixo econômico, como "subdesenvolvida", eufemismo utilizado para indicar uma condição residual, de seguidor; um estado de ser que não faz sentido algum por si só, sendo uma aproximação imperfeita e inadequada da normalidade que é a terra de origem do gringo em questão. ${ }^{10}$ No eixo cultural, a alteridade carioca é entendida como "não-ocidental" e "não-branca". Como adverte Franz Fanon, essa categorização situa a cidade no universo da sensualidade, não no das idéias e das emoções, não no da razão. ${ }^{11}$

No campo das relações sexuais entre gringos e nativos, esses entendimentos da cidade geralmente encontram expressão em três idealizações acerca dos nativos, geralmente rotulados de "brasileiros":

a) A idéia de que os brasileiros - e particularmente as brasileiras - são dotadas de uma sexualidade "natural" acentuada. Nas palavras de alguns turistas sexuais (autodenominados):

\footnotetext{
${ }^{10}$ MamdanI, Mahmood. Introduction: Thinking Through Africa's Impasse. In: Citizen and Subject. Princeton, NJ, Princeton University Press, 1996.

${ }^{11}$ FANON, Franz. Black Skin, White Masks. Grove Press, NY C, 1995 [1967].
} 
Ana Paula da Silva

Thaddeus Blanchette

Como você sabe, as brasileiras não têm medo de sexo...

Fazer sexo é como comer para as brazilianas [sic]. Vão fazer sexo de qualquer maneira, então, por que não com você?

O Brasil tem uma cultura sexual muito liberal. Já entrou num ônibus lotado no Rio? Muitas vezes os brasileiros esfregam numa menina no ônibus e os dois acabam num daqueles motéis...

Estas concepções não são diferentes daquelas apresentadas pelos gringos residentes de longo prazo na cidade e que se opõem ao turismo sexual. Esses também descrevem a sexualidade brasileira como acentuada e abundante em oposição à do "O cidente" (lembrando, novamente, que os gringos quase sempre situam o Brasil como país "não-ocidental").

As ocidentais se sentem culpadas para com o sexo. As brasileiras, não. Acho que existe uma mentalidade brasileira que é do tipo: "Temos esses corpos e devemos aproveitar".

b) A idéia de que as relações sociais expostas na cidade particularmente as relações familiares e o papel da mulher na família - são típicas de um outro tempo, o passado dos países de origem dos gringos em questão. Como dizia um gringo residente...

Gosto do Rio, pois aqui as pessoas são como eram antigamente em nosso país - no tempo de meus avós. Aqui as pessoas pensam na família e nos amigos primeiro e no dinheiro só muito depois. Isso foi uma das razões que acabaram me fazendo casar com uma brasileira: elas sabem valorizar a família, que não é algo que a maioria de americanas sabe mais fazer.

Essa opinião encontra eco nas palavras de estrangeiros que costumam vir à cidade em viagens de turismo sexual: 
sexo, turismo e deslocamento transnacional em Copacabana

Aqui as mulheres são como eram na Europa anos atrás: sabem tratar bem um homem; não competem com ele. Se vou me casar novamente, vai ser com uma brasileira, pois elas são como as mulheres de antigamente. Querem uma família, não uma carreira.

A cultura americana está passando por algumas modificações e estas têm mudado as relações entre os homens e as mulheres (...) As mulheres fizeram grandes avanços em negócios e em muitas outras áreas aqui (...) e a independência que as mulheres têm agora faz com que muitas delas não valorizam mais os homens (...) [As mulheres] são a cola da família (...) 0 americano hoje busca uma mulher que não vai competir com ele, mas que vai complementá-lo (...) A brasileira é bem simples em seus gostos e desejos e vive mais em função da simplicidade da vida e de sua família...

c) A visão da cidade como "perdedora" (também do país como "perdedor") - um espaço sócio-econômico que não provê adequadamente a maioria de seus habitantes, particularmente as mulheres. N ovamente, os turistas sexuais primeiro...

A brasileira quer um americano, pois nós temos mais status e podemos dar uma vida bem melhor a ela.

Existem tantas garotas de programa no Brasil porque, francamente, o país é um desastre. Os políticos corruptos roubam tudo, não tem emprego, está todo mundo pobre... gente morrendo de fome... Então, a maioria das garotas de programa faz o que faz, pois é isso ou a morte. São mulheres normais que fazem programas porque o Brasil é uma merda.

[E um gringo residente] O Brasil é uma nação falida ou, como disse meu amigo, "a mais imperfeita das nações"... Morar aqui no Brasil é como viver numa terra de bárbaros selvagens. É superdeprimente... Por isso, as mulheres têm tanto interesse em nós [gringos]. 
Ana Paula da Silva

Thaddeus Blanchette

Comparando as opiniões expressas por esses estrangeiros, chegamos a uma visão idealizada da cidade do Rio de J aneiro e das relações sexuais e afetivas de seus habitantes, que situa a cidade como um "campo de diversões sexuais"; nele, as mulheres são por natureza "bonitas, exóticas" e sexualmente "ativíssimas" e os estrangeiros do "primeiro mundo" são vistos como extremamente atraentes pelo fato de o Brasil ser um país "perdedor" e eles disporem de dinheiro e status. Ademais, a cidade é entendida como um espaço onde as relações familiares são destacadas e o papel feminino dentro da família é "tradicional". Importante salientar que essa visão gringa do Rio é também reconhecida e compartilhada por muitos nativos da cidade.

Portanto, embora os gringos residentes se diferenciem enfaticamente dos gringos classificados como turistas sexuais, as visões que ambos os grupos têm das possibilidades de sexo e amor na cidade são bastante semelhantes. ${ }^{12}$ Eles também compartilham de outra opinião, o que explica o comentário do residente que "não precisava ir a Copacabana": apesar de considerarem as mulheres cariocas como sexualmente ativas e disponíveis, ambos os grupos acham difícil um estrangeiro itinerante forjar um relacionamento sexual com uma "mulher normal" se não puder falar o português. Nas palavras de um de nossos informantes: "Sem falar bem o português ou viver na cidade, pode esquecer namorar uma garota normal. 0 máximo que vai conseguir é uma garota de programa, a menos que tenha amigos brasileiros que possam apresentá-lo às mulheres normais". Essa opinião encontra numerosos ecos nos depoimentos de vários gringos, itinerantes e residentes.

A possibilidade de engajarem relacionamentos sexuais e afetivos com as brasileiras, entendidos como altamente 12 Termo usado por nossos entrevistados para indicar uma mulher que não
engaje na comercialização do sexo. 
sexo, turismo e deslocamento transnacional em Copacabana

diferenciados daqueles disponíveis em seus países de origem, é uma das explicações preferenciais proferidas por gringos de todas as estirpes para explicarem sua presença no Rio de Janeiro. ${ }^{13}$ Todavia, a chance de ter acesso às "mulheres normais" - nãoprostitutas - é vista como dependente da inserção do estrangeiro em redes sociais nativas. Esta, por sua vez, é tida como sujeita às suas habilidades na língua portuguesa e à quantidade de tempo de permanência na cidade. Falando português e tendo inserção nas redes sociais nativas, um gringo terá acesso à vida sexual normativa. Não falando português e sem ter acesso às redes, é preciso ir a Copacabana.

Vamos olhar, então, os homens que "precisam ir", os gringos que são geralmente categorizados como turistas sexuais.

Na pista da Help

A boate Help fica na Avenida Atlântica, no bairro de Copacabana, e faz parte de um sistema de casas que inclui outros bares e restaurantes. Ela é freqüentada por do is grandes grupos de pessoas: estrangeiros itinerantes, geralmente da Europa e da América do Norte, e garotas de programa brasileiras. A Help é famosa, internacionalmente, como o lugar, por excelência, onde um estrangeiro pode arranjar uma garota de programa sem ser exposto à violência, aos assaltos, ou à corrupção policial. Portanto, embora a maioria dos turistas sexuais auto-identificados a definam como "cara, barulhenta e banal", todos têm ido várias vezes à boate, que um deles classifica como "a Disneylândia brasileira do turismo sexual". ${ }^{14}$

\footnotetext{
${ }^{13}$ Porém, quase nenhum gringo - mesmo os turistas sexuais assumidos - vem para o Rio só e exclusivamente para engajar em relações sexuais e/ou afetivas co m mulheres brasileiras.

${ }^{14}$ É mister salientar aqui que os autores formam um casal ideal para a tarefa de engajar em pesquisas de observação/participação no universo de turismo sexual. Ana Paula é negra, "carioca da gema" e de aparência bem jovem, enquanto Thaddeus é gringo, com fisionomia tida como "tipicamente alemã" (ou americana) e de aparência de meia idade. Também formam um casal no sentido
} 
Ana Paula da Silva

Thaddeus Blanchette

Os papéis normativos de gênero são parcialmente invertidos dentro da boate, fato que muitos dos homens entrevistados citam como grande atrativo da casa: o aliciamento dos homens por parte das mulheres passa a ser a regra. Vários de nossos informantes dizem ter experimentado algo semelhante ao que imaginam ser "a vida de uma estrela de rock: as mulheres caem em cima de você e não te largam".

O centro das atenções na boate é a pista de dança. Normalmente, as mulheres a utilizam para demonstrar seus dotes físicos, enquanto os homens ficam em torno, assistindo. Quando vê uma mulher que 0 atrai, o homem entra na pista para dançar com ela. Às vezes, uma mulher puxa um homem que a observa para a dança. Nestes casos, o aliciamento feminino varia entre 0 bastante explícito e o convincentemente ingênuo, de acordo com a leitura da mulher dos prováveis gostos de seu espectador.

A pista é o local privilegiado para a negociação de serviços sexuais. "Atrevida" ou "ingênua", enquanto estão com os homens, as "meninas" ${ }^{15}$ aumentam a sensualidade de seus passos, ensaiando reboladas e se esfregando no parceiro. A performance

afetivo da palavra, sendo namorado e namorada. Portanto, as investigações relatadas aqui seguiam uma etnometodologia invertida: embora nós nunca nos apresentávamos como turista e garota de programa, constantemente éramos assim percebidos. Através disso, conseguimos acesso a muitos lugares e situações e poderíamos observar os comportamentos dos nativos sem grandes distúrbios a seus rituais. Todavia, quando as pessoas perguntavam sobre nossa presença e atividades sempre deixávamos claro que éramos pesquisadores antropológicos. Vale a pena salientar que a técnica de observação-participante não implica em imitar tudo que os nativos fazem, mas simplesmente participar na sociabilidade cotidiana deles. Destacamos que nenhum de nós dois contratou, ou intermediou, serviços sexuais no decorrer dessa pesquisa. Para o conceito de etnometodologia, vide GARFINKLE, Harold. Studies in Ethnomethodology. NJ ., Prentice-H all, Englewood Cliffs, 1967.

15 "Menina" ou "garota" é termo usado pelas próprias mulheres, trabalhadoras de sexo, para se mesmo e para outras em sua profissão. Usamos o termo neste sentido. 
sexo, turismo e deslocamento transnacional em Copacabana

só pára quando o casal fecha o negócio, vai a uma mesa para "se conhecer melhor", ou quando um dos elementos do par geralmente o homem - deixa a parceira sozinha na pista.

A maioria dos homens que freqüenta a casa é relativamente jovem (entre 30 e 40 anos), de boa aparência ${ }^{16}$ e da classe média. Aproximadamente $10 \%$ seriam classificados como negros, seguindo as normas dos EUA, e de acordo com os relatos dos freqüentadores, essa porcentagem vem aumentando sensivelmente nos anos recentes. É difícil afirmar qual é a origem da maioria dos gringos, mas a língua estrangeira mais falada na boate é 0 inglês, sendo que os avisos nas portas da casa vêm escritos nesta língua, em português, espanhol, alemão e italiano. A maioria das mulheres, por sua vez, é de pele morena, embora sempre há uma grande quantidade de mulheres classificadas como "brancas" e "negras" e jovens pelos outros freqüentadores da casa. A idade parece variar entre 18 a 45 anos, com uma média provável de 25 anos. A casa pode pedir as identidades das mulheres na entrada e se existem menores dentro da Help, estas são cuidadosamente produzidas para passarem por adultas. Em nenhuma de nossas idas constatamos a presença evidente de menores de idade dentro da boate.

Tipos de turistas sexuais

Existem indicações de que muitos estrangeiros acabam na Help precisamente porque 0 sexo é entendido como um componente necessário de uma visita bem-sucedida à cidade, algo que quase se assemelha a uma "lembrança típica" do Rio. ${ }^{17}$ Nas

\footnotetext{
${ }^{16}$ Aqui adotamos uma categoria utilizada na Help para descrever homens que são considerados bonitos de acordo com o padrão dominante da sociedade ao seu redor. Ou seja, homens que não estão obviamente fora de forma, idosos, ou obesos, que se vestem com roupas razoavelmente novas e limpas e que demonstram um grau razoavelmente alto de higiene corpo ral.

${ }^{17}$ Ribeiro, M. A. C. Prostituição Feminina e Turismo na cidade do Rio de Janeiro. In: Turismo e Cultura, a história e os atrativos regionais. Porto Alegre, Ed. Santo Ângelo, URIAUM/FAPERGS, 2001.
} 
Ana Paula da Silva

Thaddeus Blanchette

palavras de um de nossos informantes gringos, em passagem pela cidade:

Nunca fiquei com uma prostituta lá em casa, mas aqui... Poxa, estou no Rio de Janeiro! Como posso deixar a oportunidade passar?

[Outro informante, inglês, em viagem de turismo pelo Rio, foi mais explícito ]

Um colega meu veio ao Rio no ano passado. Ficou falando de como conseguiu comer cada gata por aqui... Falava que era só estalar seus dedos e oh! mulher vinha correndo. Falava que era como viver um filme de pornografia 24 horas por dia. Então, marquei de voltar junto com ele e aqui estou. Só que descobri uma coisa: o safado não dizia que essas mulheres eram todas putas! Fiquei desiludido, cara, e acabei viajando para Paraty e Cabo Frio por três semanas. Não consegui nada lá... Então, como tenho que voltar à Inglaterra amanhã, estou aqui [na Help], né? Afinal, como é que eu posso voltar para o escritório e dizer que fui ao Brasil e não comi ninguém?

Este é o primeiro tipo de homem encontrado na Help - e talvez o tipo mais numeroso. Nós o chamamos de turista sexual acidental, pois ele atribui sua presença na boate à força das circunstâncias e não a considera fruto de um plano ou o objetivo final de sua viagem. G eralmente, o turista sexual acidental explica o fato de estar à procura de garotas de programa pela conjuntura de estar no Rio (cidade onde o sexo livre e abundante é tido como "normal") e de, inexplicavelmente, não ter conseguido as parceiras sexuais que esperava encontrar entre as mulheres normais (não-prostitutas). Também podem ser incluídos nessa categoria os marujos, os trabalhadores dos campos de petróleo da Bacia de Campos e os funcionários expatriados de grandes corporações internacionais. A presença deste terceiro grupo é um pouco surpreendente, pois são homens que têm uma inserção 
sexo, turismo e deslocamento transnacional em Copacabana

relativamente profunda nas redes sociais nativas da cidade. Todavia, eles podem ser divididos em duas subcategorias: os que não sabem falar português e os que são casados. Membros do primeiro grupo encontram dificuldades em arranjar parceiras por falta da habilidade lingüística. Os membros do segundo afirmam preferir procurar prostitutas quando suas mulheres estão fora da cidade, pois "arranjar uma namorada é perigoso: ela vai ficar te telefonando e eventualmente causará um escândalo quando a esposa voltar. Por isto, vou à 'zona'."

O segundo tipo de homem encontrado na Help faz parte de um grupo pequeno, mas expressivo: os auto-rotulados mongers ${ }^{18}$, turistas sexuais assumidos e que gastam enormes quantidades de tempo e de dinheiro à procura de novas aventuras sexuais. Fisicamente, não se diferenciam dos outros na boate. Moralmente, apresentam-se mais categoricamente contra eventuais violações dos códigos sexuais legais brasileiros do que os turistas sexuais acidentais, não porque eles se preocupem com as conseqüências sociais de seus atos, mas porque são conscientes de que estes os deixam expostos às acusações de ordem legal-jurídica e vulneráveis às doenças e à violência.

Os mongers reclamam de serem mal-entendidos. Salientam o fato de que a auto-prostituição de adultos no Brasil não é ilegal e enfatizam que não fazem nada diferente de milhões de brasileiros - inclusive alguns membros do Congresso Nacional. A atitude desses homens em face do seu comportamento é bem expressa na etimologia de um dos nomes mais comuns que têm escolhidos para si mesmo - hobbyist - alguém que exerce um passatempo.

De fato, o comportamento dos mongers é bastante semelhante ao de maníacos por futebol, golf, ou jogos de RPG só para nomear alguns passatempos recreativos que mobilizam legiões de fãs, geralmente masculinos. Como esses outros homens,

\footnotetext{
${ }^{18} \mathrm{~A}$ palavra vem de whoremonger - alguém que compra ou vende os serviços de prostitutas.
} 
Ana Paula da Silva Thaddeus Blanchette

os mongers também gastam recursos num passatempo que só aumenta o prestígio do hobbyist dentro do universo fechado de seus semelhantes. O'Connell Davidson ${ }^{19}$ atribui o comportamento de turistas sexuais contumazes a uma competição de prestígio generalizada entre homens. No entanto, observamos que os mongers são bastante cautelosos em escolher a quem falar sobre as suas atividades. O "prestígio" do hobby só tende a ser reconhecido entre os outros adeptos do passatempo e eles estão bastante cientes quanto a este fato.

É provável que existam tantas razões para ser um monger quanto mongers, mas as freqüentemente expressas são as seguintes:

1. Toda mulher é prostituta (...) Portanto, pagando uma prostituta de verdade, você pelo menos está fazendo uma transação com uma mulher honesta.

2. Pago, de fato, para a mulher ir embora no dia seguinte sem me pentelhar sobre um relacionamento.

3. Eu preciso de sexo com muitas mulheres diferentes. Mulher é como batata chips: uma só não me satisfaz.

4. Quero transar com todo tipo de mulher no mundo antes de decidir qual é a melhor para casar. Assim, consigo comer asiáticas, mulatas, negras, brancas, ruivas...

5. Estou ficando velho [nesse caso, 40 anos] e não consigo pegar as meninas como antigamente, mas não estou a fim de diminuir meu ritmo sexual, nem escolher uma só mulher.

6. Não tenho paciência para o papo furado. Quero saber que no final da noite vai ter uma trepada. Onde é que posso ter essa certeza senão aqui [na Help]?

19 O'Connel Davidson, Julia. Prostitution, Power and Freedom. Ann Arbor, University of Michigan Press, 1998. 
sexo, turismo e deslocamento transnacional em Copacabana

Mas a nossa explicação favorita para o comportamento foi oferecida por um dos nossos informantes americanos: "Por que é que alguém vira monger? Porque pode, ora!"

Enfim, o poder, como salienta $\mathrm{O}^{\prime} \mathrm{C}$ onnell Davidson, é sine qua non na existência do monger. ${ }^{20} \mathrm{No}$ entanto - o que tem escapado à visão de muitos analistas do turismo sexual -, esse poder é análogo ao daquele que um turista "normal" exerce quando recebe os serviços de uma camareira que é paga com um salário mínimo. Num mundo dividido em instâncias sócio-políticas diferenciadas de prestígio e de poder, onde o capital voa livremente através das fronteiras, mas o movimento das pessoas é restrito "a quem pode", o monger configura-se como mais um turista que paga um preço irrisório por um serviço amplamente ofertado no país de destino. É interessante notar que os mongers justificam suas atividades da mesma maneira que os estrangeiros que freqüentam os "favela tours" do Rio de Janeiro: salientam que estão conhecendo algo "típico" da cidade e que o dinheiro que gastam "vai para os necessitados".

Exploração de menores e tráfico de mulheres

Determinar quem pode ser - ou não - menor de idade na gira da noite de Copacabana não é fácil. Quase todas as garotas de programa atuando na noite apresentam-se como maiores de idade e adotam um visual de acordo com isto. Em oito meses de pesquisa, encontramos poucas garotas que nos pareciam ser claramente menores de idade - nunca mais que $2 \%$ das nossas contagens noturnas de prostitutas -, mesmo assim, somente em momentos de grande movimento. A vasta maioria das garotas trabalhando como prostitutas na orla de Copacabana aparenta ter mais de 18 anos.

$N$ ão encontramos nenhum gringo que buscasse sexo com menores de idade. Muito pelo contrário: quase todos os websites

\footnotetext{
20 ID., IB.
} 
Ana Paula da Silva

Thaddeus Blanchette

dos mongers contêm advertências contra a exploração sexual de menores. Muitos dos homens que conhecemos manifestaram fortes opiniões contra a prática, afirmando estarem buscando "encontrar mulher. Não tenho interesse algum em menininhas e os caras que têm merecem porrada".

Embora não tenhamos encontrado nenhuma articulação estrutural necessária entre a exploração sexual infanto-juvenil e a interseção entre sexo e turismo em Copacabana, nossas pesquisas indicam que o mesmo não pode ser claramente afirmado em relação ao assim chamado "tráfico das mulheres", pois os movimentos internacionais abaixo descritos podem ser considerados como tráfico de acordo com determinadas definições do conceito, que confundem as migrações de trabalhadoras sexuais com tráfico de mulheres. 0 fato é que eventuais viagens ao exterior por parte das meninas são vistas como nada surpreendentes em boates como a Help. Todas as nossas entrevistadas dizem ter ido ao exterior para trabalhar ou namorar, ou estão esperando ir. Muitas se casaram ou noivaram com gringos que encontraram na noite de Copa. A expectativa das nossas entrevistadas é que a prostituição possa ser transformada e/ou suplementada com relacionamentos afetivos com gringos clientes ou não - e que estes resultem em viagens ao exterior. Para entender melhor esse drama e para apresentar o terceiro tipo de homem atuante na Help, fazemos uma pequena passagem pelo banheiro feminino da boate.

A arte de se preparar para a encenação no banheiro da H elp

0 banheiro feminino é um lugar importante no drama encenado na boate Help. Local pouco explorado nas etnografias escritas sobre prostituição, este ambiente tem se mostrado um espaço revelador das relações sociais que são estabelecidas na boate como um todo. 
sexo, turismo e deslocamento transnacional em Copacabana

0 fato de um dos pesquisadores ser mulher proporcionou um acesso facilitado a este espaço. Destacamos que em nenhum momento a pesquisadora se apresentou a outras mulheres como garota de programa: simplesmente apareceu entre elas como mais uma mulher em busca do banheiro. Todavia, era óbvia que esta não era a visão que elas tinham da pesquisadora. Como disse o sociólogo Peter Berger ${ }^{21}$, as interpretações do nativo em relação à presença do pesquisador no campo nunca são destituídas de algum juízo de valor por parte daqueles com quais o etnógrafo está interagindo. Em nosso caso, não foi diferente. Muitas vezes, a pesquisadora teve a certeza de que as mulheres por ela encontradas no banheiro acharam que ela também fosse garota de programa, não pela roupa, maquiagem ou linguajar, mas pelo fato ficar próxima ao biotipo e às condições da maioria das meninas que ali estavam: mulher jovem, negra ou morena, e acompanhada por um homem de origem estrangeira.

A dramaturgia ressalta o banheiro público como importante espaço de negociações entre mulheres. Essa idéia tem sido veiculada em comerciais, telenovelas e comédias do cotidiano. A visão masculina é sempre a de que o banheiro feminino é 0 espaço de conversa e de planejamento de tramas. A forma como as mulheres vão ao banheiro - normalmente juntas - e 0 fato de que também demoram lá aguçam a curiosidade sobre 0 que realmente acontece nesse lugar que é só delas. Portanto, existe um imaginário sobre o banheiro feminino como um local importante para tecer redes de relações femininas. Dentro deste contexto, pode-se entender por que o banheiro feminino da Help se torna um lugar estratégico para observar as garotas de programa da casa. É um espaço onde as tramas da noite são discutidas em alto e bom tom, sem a presença de testemunhas masculinas. 0 banheiro, enfim, é um "camarim", um local onde atrizes preparam falas, gestos, movimentos, maquiagem, olhares e onde também podem exprimir sentimentos, desejos e sonhos.

${ }^{21}$ Berger, Peter. Perspectivas Sociológicas. Petró po lis, Vozes, 1988. 
Ana Paula da Silva

Thaddeus Blanchette

Camarim: espaço para a preparação do espetáculo

A idéia de camarim significa recinto do teatro, onde os atores se preparam. ${ }^{22}$ Dentro desta lógica, é possível entender que este lugar é fundamental para o ator poder desempenhar uma boa performance no espetáculo. É neste sentido que argumentamos sobre a possibilidade de pensar o banheiro feminino da Help como camarim, pois ele se constitui em um excelente lugar para "revelações e ensaios", em que cada um se prepara para encenar seu personagem em mais uma noite no palco - a pista dançante da Help.

Um fato marcante do banheiro feminino da Help é que nele circula um corpo de assistentes. Normalmente, essas pessoas são funcionárias do caixa, da limpeza, mas adotam também o papel de esteticista para ganhar um dinheiro extra com as meninas freqüentadoras. No fundo do banheiro, havia uma moça que possuía uma grande variedade de maquiagens. Alugava itens de seu estojo e, muitas vezes, ajudava a preparar as meninas, pintando-as e escolhendo tons adequados para a sua roupa, o seu tom de pele e de cabelo. Para esses serviços, eram cobrados $R \$$ 2,00 para cada produto utilizado. Uma segunda mulher cuidava da arrumação do cabelo das meninas, utilizando pentes, gel e secadores para montar o penteado. Uma terceira vendia roupas e acessórios para compor e completar o visual. Todas as três assistentes também vendiam preservativos, balas, chicletes e cigarros.

É importante salientar que existe uma abertura para o comércio desses produtos dentro do banheiro, pois ninguém pode entrar na casa portando bolsa. Estas ficavam retidas na entrada; portanto, as meninas entravam desguarnecidas de maquiagem e outras coisas de que poderiam precisar. Neste sentido, é possível entender porque 0 banheiro se transformava em um grande

22 Brandão, J unito de Souza. Mitologia G rega. Petrópolis, Vozes, 1991. 
sexo, turismo e deslocamento transnacional em Copacabana

mercado de produtos e de acessórios vendidos pelas funcionárias da boate. Como em qualquer salão de beleza feminina, as clientes costumam falar com aquelas que as atendem e entre si durante os preparativos.

Os diálogos versavam desde a discussão dos capítulos de novelas até a negociação de preços entre clientes. Todas cobravam, nesse tipo de atendimento, em torno de U\$100 na moeda norte-americana, de preferência (os preços em reais eram sempre mais altos). 0 banheiro, então, era uma peça-chave na reprodução do comércio do amor, pois ali as meninas podiam estabelecer entre si, no vai-e-vem da conversa, o que era considerado "um preço justo", conforme o movimento do dia.

Um fato, porém, impressionava mais nas conversas entre as meninas no banheiro: as suas descrições das relações desempenhadas com seus "namorados estrangeiros". 0 assunto, em algum momento, sempre desembocava na idéia de casamento. Este procedimento pode ser pensado a partir de alguns aspectos que passamos a descrever.

Em uma de suas primeiras incursões no banheiro, a pesquisadora prestou atenção numa conversa entre as meninas em que falavam em uma conhecida que "conseguiu um gringo" 23 e foi para a Europa, casando-se com ele. A partir disso, começávamos a perceber que a possibilidade de casamento entre as meninas e os estrangeiros freqüentadores da Help fazia parte do cotidiano vivido pelas mulheres. Em outro momento, a pesquisadora observou uma conversa entre uma moça e a camareira que ajeitava sua roupa. A menina pedia à outra para reparar se sua barriga já estava aparecendo e a camareira respondia:

\footnotetext{
${ }^{23}$ Expressão utilizada pelas meninas. Conota a criação de um laço mais-quepassageira entre uma menina e um estrangeiro, geralmente vindo da Europa ou da América do Norte.
} 
Ana Paula da Silva

Thaddeus Blanchette

\begin{abstract}
Você está ótima! Nem parece que está grávida. [Neste momento, a pesquisadora virou-se para a moça e a interrogou] Nossa! Você está grávida?

Sim [respondeu a garota]. Demorei seis meses para pegar aquele americano, mas finalmente consegui. Agora estou esperando ele voltar para os Estados Unidos para eu ir embora junto.

Mas ele sabe que o filho é dele? Ele vai assumir? [perguntou a pesquisadora]

Lógico! Ele não é nem besta de não assumir. Estou cuidando muito bem do meu americanozinho aqui [alisando a barriga] e vou para os Estados Unidos me casar com o pai dele.
\end{abstract}

Ouvindo a conversa, a camareira então avisou: "Cuida mesmo, porque você teve uma sorte de ouro". A moça saiu do banheiro radiante com a certeza de vitória e com a possibilidade de migrar.

Interpretando as falas do camarim

Esses relatos demonstram que a estratégia de casamento, visando ir para o exterior, não é impensada ou algo que necessita de um "aliciamento", como pressupõe determinadas noções do "tráfico de mulheres". As meninas da Help têm consciência do passo que dão com essa decisão e que ela pode acabar naufragando. A união entre as prostitutas e seus clientes é vista por elas como estratégia interessante no que diz respeito à sua posição profissional e/ou pessoal e às oportunidades que possam se abrir a partir daí. Às nossas perguntas sobre o que elas fariam se 0 relacionamento não desse certo, houve uma resposta unânime: "ou a gente volta para o Brasil e continua trabalhando aqui, ou passa um tempo trabalhando na Europa, onde 0 programa paga bem melhor". 
sexo, turismo e deslocamento transnacional em Copacabana

A predileção das meninas por gringos não é um mero acaso, muito menos uma opção feita por falta de informações ou por "baixa estima". Num mundo onde o acesso ao exterior é cada vez mais restrito, especialmente para brasileiras pobres, estes homens aparecem como meios de abrirem as rotas para a Europa e os Estados Unidos, onde - no imaginário, mas também na experiência de muitas das meninas - as oportunidades existem. Neste quadro, não importa muito se o casamento vai dar certo ou não, pois de qualquer maneira ele traz uma chance de trabalhar nos países metropolitanos onde as mulheres costumam ganhar um rendimento bem mais alto do que no Brasil.

Todas as nossas informantes afirmam trabalhar por conta própria. De acordo com uma delas,

o único momento em que cafetão entra no jogo é quando você quer viajar para o exterior. Aí, tem que pagar para alguém te oferecer um trabalho legítimo para conseguir a entrada. Se já foi deportada, tem que pagar a alguém para ajeitar as coisas com a polícia federal (...) Enfim, é muito dinheiro que a menina gasta com cafetão quando quer trabalhar lá fora, a menos que consiga arranjar um convite de algum amigo gringo.

O casamento, ou mesmo a oferta de casamento, pode eliminar o papel do cafetão da vida da menina durante 0 deslocamento internacional. Neste sentido, "fazer amores" significa um poderoso recurso na busca de uma saída para o exterior. Longe de ser fruto de um aliciamento estrangeiro ao tráfico, namoros que resultam em viagens internacionais são cultivados por muitas garotas de programa em Copacabana, precisamente porque podem eliminar a necessidade de procurar a ajuda paga de terceiros na imigração ilegal.

Uma outra jogada estratégica bastante empregada pelas meninas é procurar no gringo a aposentadoria. A vida profissional útil de uma prostituta é semelhante a dos jogadores de futebol: geralmente vai até os 30 anos, pois nesta idade o peso de ter que 
Ana Paula da Silva

Thaddeus Blanchette

competir com as mais jovens começa a se impor. Além disto, a prostituição em si é desgastante. Muitas meninas reportam trabalhar do meio-dia até as seis da manhã. O consumo de bebidas alcoólicas e drogas é constante e quase obrigatório. Todos estes fatores combinam para limitar dramaticamente o exercício da carreira de garota de programa. Nesta situação, o casamento com um homem com uma vida economicamente estável pode significar uma oportunidade viável para a mulher sair do comércio do sexo. Melhor ainda se o homem for gringo, pois a vida conjugal pode ser vivida no exterior, significando um renascimento social da mulher que adotará uma reputação de mulher normal, não-prostituta.

É possível ressaltar que as conversas no banheiro feminino abrem brechas para pensar sobre 0 real poder das mulheres no jogo do turismo sexual. A descrição acima deixa claro que suas posições não necessariamente são de vítimas indefesas ou objetos passivos traficados entre universos subordinados e dominantes. A comparação aqui do banheiro feminino com um "camarim" é justamente para chamar a atenção de como cada ação é pensada e interpretada dentro da boate, pois uma boa negociação das possibilidades da pista pode representar mobilidade internacional e até ascensão social.

Turistas de amor

0 terceiro tipo de gringo que freqüenta a Help é o que chamamos "o turista de amor", seguindo a auto-denominação de três de nossos informantes.

O consenso entre os mongers dá-se conforme a opinião brasileira: todas as mulheres que freqüentam a Help (fora as funcionárias da casa) estão disponíveis para 0 sexo comercializado. Todavia, existe uma minoria gringa que insiste no fato de muitas mulheres normais também freqüentarem a boate 
sexo, turismo e deslocamento transnacional em Copacabana

Help à procura de namorados. Esse grupo classifica a boate como lugar excelente para se buscar uma futura esposa.

Ouvimos essa afirmação pela primeira vez em uma discussão pública, quando um gringo se auto-classificou como um turista de amor - e não de sexo -, pois tinha conhecido "sua noiva" na Help, descrevendo-a como baiana, de 26 anos de idade e virgem. Como era de se esperar, a reação da maioria dos participantes da discussão variou entre o ceticismo aberto e as risadas plenas. Um deles opinou que o homem deveria ter encontrado o "avatar" da Nossa Senhora de Copacabana, sendo esta a única resposta possível à questão de como uma virgem poderia ter sido encontrada na Help.

Originalmente, classificamos este caso como excepcional, mas no decorrer das nossas pesquisas, conforme relatado acima, descobrimos que existe, de fato, um mercado matrimonial significativo na boate. Ademais, vários de nossos informantes disseram ter testemunhado casos semelhantes ao do homem e da "Nossa Senhora da Help". Uma informante nos ofereceu até uma receita para simular a virgindade. Finalmente, entrevistamos uma garota de programa que nos deu um depoimento em que a nossa "etnometodologia invertida", mais uma vez, funcionou a nosso favor.

Kika disse que tinha ido à Alemanha uma vez "para casar com o amor da minha vida", mas que isto não tinha dado certo. Perguntamos, então, se era verdade que muita menina acabava se casando com gringo.

Não é não. É mentira. Quer dizer, é possível. Pode acontecer, mas é muito difícil. Tem que ser, tipo... tem que ser tipo vocês [apontando para o casal de pesquisadores].

Como "tipo nós"? [indagamos]

Tem que ser o amor à primeira vista, que nem vocês, [respondeu Kika, virando para encarar a pesquisadora que ela claramente identificava como outra prostituta] Quero dizer, quando você viu ele pela primeira vez não foi o 
Ana Paula da Silva

Thaddeus Blanchette

amor? Você não olhou para ele e sabia que ele era o homem pelo qual você esperava toda sua vida? [A pesquisadora inclinou a cabeça ambiguamente e disse, muito antropologicamente] Bem...

Foi, sim [afirmou a Kika]. Tem que ser assim, que nem vocês. A menina só pode ter olhos para o cara e nenhum outro homem. Ela não pode bobear, ficar dando mole para outros enquanto ele estiver presente [ênfase nossa]. É isto que essas piranhas jovens não entendem: se vai encontrar o amor de sua vida, não pode bobear, não.

Analisando o testemunho da Kika, percebemos que ela nos tinha oferecido o receituário de como as meninas podiam agir para transformar cliente em namorado. É impossível dizer se a categoria amor da minha vida é ou não é empregada de forma sincera pelas garotas. Todas as nossas informantes femininas que tocaram nessa questão classificaram "seus" amores como verdadeiros e os amores das "outras" como falsos. Várias admitem ter manipulado a ilusão de amor para fins lucrativos. Todavia, é mister lembrar que atuar como prostituta não proíbe a possibilidade de amar. Ademais, o amor, embora popular e romanticamente visto como um processo espiritual recíproco e que o amante não consegue controlar, é uma coisa largamente criada pela intervenção ativa dos parceiros. Como Berger e Kellner salientam, amor é uma poderosa relação nômica e totalizante que estrutura nossos entendimentos básicos do mundo. No amor, dois indivíduos se juntam num ato dramático em que eles são redefinidos social e psicologicamente. Um terceiro pode acusar insinceridade, mas como o amor é vivido como uma realidade essencialmente compartilhada a dois, é impossível - 
sexo, turismo e deslocamento transnacional em Copacabana

ausente algum ato público e dramático - um terceiro comprovar sua ausência. ${ }^{24}$

Impossível também dizer se os gringos envolvidos nessas "histórias a dois" acreditam nelas. Muitos homens nos têm dito que sabem que suas namoradas eram prostitutas, mas agora que encontraram um cara legal largaram a vida. Outros, casados com uma ex-prostituta, culpam o Brasil pelo fato de sua mulher ter feito programas. Nessa visão das coisas, foi a pobreza e a falta de oportunidades econômicas para as mulheres no Brasil que as forçaram a se prostituírem. Todavia, como Gaspar salienta, a modificação da história de vida para pormenorizar o ônus de prostituição é um recurso "pronto e preparado" das garotas de programa de Copacabana:

[A mulher se apresenta como] uma mulher/personagem fraca, que por força do destino encontra-se nessa situação e necessita de proteção ou auxílio econômico. 0 relato enfatiza a posição inferior da mulher e a situação conjuntural de extrema fraqueza que obriga a sua dedicação à prostituição, atividade que ele repudia (...) Uma informante [de Gaspar], Luísa, é bastante explícita sobre esse procedimento. Para ela, existe um modo de entrar em interação com o cliente e uma fórmula de pedir o pagamento: "Você conta uma história bem triste (...)"

$N$ ão quero com isso afirmar que algumas mulheres não tenham sido induzidas ou mesmo forçadas (...) a se dedicarem à prostituição, mas sim que sua própria história de vida ou uma outra construída dramaticamente tornou-se um elemento fundamental na interação com o cliente. ${ }^{25}$

\footnotetext{
${ }^{24}$ Berger, P. \& Hansfield, K. Marriage and the Construction of Reality. In: Marriage and Family in a Changing Society. NYC, The Free Press, 1980, pp.165166.

${ }^{25}$ GaSPAR, M. D. Garotas de Programa... Op. cit., pp.93-94.
} 
Ana Paula da Silva

Thaddeus Blanchette

Esta explicação nos parece bastante adequada para entender o comportamento observado. A própria condição do país apresenta-se como outro recurso dramático para a garota de programa no relato de sua "história bem triste" para um estrangeiro. Não é de surpreender, então, que muitos de nossos informantes, cientes dos passados de suas noivas, os entendam em função da visão de um Brasil perdedor, país que força as moças de família a se prostituírem. Em tal visão do mundo, o turista de amor vê-se como um cavalheiro branco, chegando para salvar a donzela decaída, conseguindo ver uma princesa onde os demais só vêem uma meretriz.

Do outro lado da moeda, não podemos aceitar como verídicas todas as declarações gringas de amor. Como O'Connell Davidson salienta - e nossa pesquisa confirma - uma nova e crescente modalidade de turismo sexual envolve a construção da ilusão de namoro ${ }^{26}$. Tal forma de prostituição é chamada de girlfriend experience ${ }^{27}$ pelos mongers, e consiste na contratação dos serviços sexuais de uma mulher por um tempo extensivo, tais serviços podendo eventualmente incluir viagens ao exterior. 0 intuito do girlfriend experience é a vivência como um casal, sendo entendido que, após paga a quantia negociada, o homem pode ir embora na hora em que quiser. Em muitos casos, essa forma de prostituição fica ainda mais ambígua, pois o preço não é negociado de antemão, a menina confia que seu "namorado" vai Ihe pagar uma quantia justa no final de suas férias. Tais relações são muitas vezes objetivamente indistinguíveis dos relacionamentos recíprocos, nomeadamente anticomerciais e entendidos como "normais", especialmente num mundo desigual onde o parceiro gringo, parte de um casal binacional, quase sempre disponibiliza de mais dinheiro e de recursos que o parceiro

\footnotetext{
${ }^{26}$ O'Connel Davidson, J. Prostitution, Power and Freedom. Op. cit.

27 "G irlfriend experience" é também usado para designar um ato sexual pago de curta duração, que não parecia baseado na lógica do comércio e sim do amor.
} 
sexo, turismo e deslocamento transnacional em Copacabana

brasileiro. Nossas informantes, aliás, estão todas de acordo: "ganha-se muito mais como namorada do que como puta". Tal afirmação desmantela a noção que reside na base de todas as definições de turismo sexual descritas acima: a de que existe uma linha bem definida entre os comportamentos da exploração sexual comercial e aqueles entendidos como próprios aos relacionamentos normais e recíprocos.

Conclusão

Os resultados de nossa pesquisa conduzem a problematizar o discurso estereotipado sobre turismo sexual e sobre a vinculação entre migração feminina em contextos de turismo sexual e tráfico de mulheres. Esse discurso cristaliza e simplifica histórias humanas reais, apresentando-as somente no momento em que um crime supostamente acontece, situando agentes complementares em papéis distintos de vitimizada e vitimizador, seguindo uma lógica moralista, machista e nativista. Ele trata a categoria turista sexual como se ela fosse homogênea ou auto-explicativa. Todavia, como acabamos de demonstrar, existem muitos tipos de estrangeiros itinerantes sexualmente ativos no Rio de J aneiro. 0 termo turista sexual é inadequado para descrever esses homens, mesmo nos casos em que eles procuram o sexo comercializado, pois o complexo de valores que orienta as ações da maioria deles não pode ser claramente separado daquele que orienta os supostos turistas normais. 0 discurso também reduz as mulheres envolvidas nesse universo a objetos passivos, bens que são potencialmente traficados. Pior, não descreve - e muito menos explica - o cunho dos relacionamentos forjados no âmbito do turismo sexual e que pode resultar no deslocamento internacional dessas mulheres.

Como temos visto acima, as mulheres que operam na interseção entre turismo internacional e sexo são ativas na manutenção de uma visão do Brasil como campo para as realizações de fantasias sexuais e afetivas. Longe de serem simples vítimas, elas detêm um controle notável sobre as suas ações e 
Ana Paula da Silva

Thaddeus Blanchette

representações, lançando mão de vários artifícios para construírem uma almejada ascensão social através do forjamento de ligações com estrangeiros itinerantes. Suas atividades não podem ser entendidas simplesmente como os resultados de uma "lavagem cerebral colonialista", ou os frutos de uma "baixa auto-estima" ${ }^{28}$, pois freqüentemente providenciam mudanças socioeconômicas em suas vidas que são entendidas por elas como melhorias. Portanto, são melhor entendidas como estratégias racionais do que como manifestações ideológicas de uma falsa consciência.

Não queremos afirmar que as garotas de programa de Copacabana são necessariamente mercenárias calculistas, muito menos que todos os estrangeiros sexualmente ativos no Brasil são clientes de prostitutas. Nosso principal intuito aqui é trazer para as discussões sobre turismo sexual o fato observado de que existem muitas sutilezas no vai-e-vem entre prostituta e cliente que se confundem com as manifestações afetivas entre homens e mulheres entendidos como normais. Essas relações vão além do estabelecimento de meras vítimas e vilões - ou até de clientes e dos que providenciam os serviços sexuais.

Como nossos informantes salientam - e os trabalhos de outros pesquisadores, como Renata Melo Rosa ${ }^{29}$, afirmam - 0 amor gera deslocamentos internacionais de mulheres brasileiras. As prostitutas também amam e também viajam, mas 0 artigo 231 do Código Penal Brasileiro define o crime de traficar mulheres como ajudar qualquer mulher que vá exercer a prostituição no exterior a sair do território nacional. ${ }^{30}$ Tal definição ignora 0

\footnotetext{
${ }^{28} \mathrm{Um}$ exemplo da tese de "baixo auto-estima" e "colonização" pode ser encontrada em GIACOMI, Sonia Maria. Quando a mulata que não está na mapa ganha o mundo. In: Tráfico de Mulheres é Crime! Rio de J aneiro, CEAP, 1995.

${ }^{29}$ RosA, Renata Melo. Tráfico internacional das mulheres e exclusão racial. Dissertação de Mestrado, IFCS, UFRJ , 1999.

${ }^{30}$ CECRIA. Tráfico de Mulheres, crianças e adolescentes para fins de exploração sexual no Brasil. Relatório Final de Projeto de Pesquisa (PESTRAF), Brasília, 2002, p.176.
} 
sexo, turismo e deslocamento transnacional em Copacabana

habitus da prostituição em Copacabana, onde o amor e o sexo comercializado são duas faces da mesma moeda. 0 amor pode ser eterno, pode ser por uma noite, ou pode ser totalmente fingido; todavia, não existe maneira objetiva de distinguir entre um tipo de amor e o outro. Portanto, fora a proibição plena de relações amorosas e/ou sexuais entre brasileiras e estrangeiros, parece-nos muito pouco provável que a atual legislação possa prevenir o tráfico de mulheres, desde que isto continue a ser definido como sinônimo de viagem internacional de prostituta.

Em Os Elementos Básicos de Parentesco, Lévi-Strauss observa que o fato de muitos homens considerarem as mulheres como objetos de status, cabíveis de serem intercambiados, não nega a existência das mulheres como criadoras e manipuladoras de símbolos. 0 jogo das paixões que observamos na Help é construído em cima de muitas desigualdades estruturais - entre os sexos, entre o Brasil e os países metropolitanos, entre uma feminilidade brasileira concebida como mulata exótica e sexy e uma masculinidade estrangeira vista como branca e rica. Mas nenhum desses fatores, por si só ou em conjunto, é capaz de dar conta dos comportamentos observados sem levar em consideração as subjetividades envolvidas no jogo e a totalidade das opções que os atores pensam manipular. Em tal jogo, prostituta pode transformar-se em namorada ou até em esposa; turista sexual, em marido; as relações de comércio, em relações entendidas como recíprocas, conforme os projetos e performances dos atores. A natureza deslizante, complexa e bilateral dos diversos relacionamentos observados no nexo turismo, sexo e imigração na Help demonstra a necessidade de se abandonar a categoria de turista sexual como algo explicável através de grandes categorizações maniqueístas. 